\title{
An orchard invisible: Hidden seeds of wisdom in the English and Croatian proverbial apples
}

\author{
Draženka Molnar \\ J. J. Strossmayer University, Faculty of Humanities and Social Sciences, Osijek, Croatia \\ drazenka.molnar@gmail.com
}

Dubravka Vidaković Erdeljić

J. J. Strossmayer University, Faculty of Humanities and Social Sciences, Osijek, Croatia dvidakov@inet.hr

\begin{abstract}
In the paper we analyse humorous modified proverbs in light of the theory of conceptual integration. Unlike traditional proverbs, which teach us something and elucidate some aspects of human life, modified proverbs are here primarily to entertain us. The theory of conceptual integration is particularly suitable for the interpretation of modified proverbs since they present novel structures that are not part of our mental lexicon and which we need to interpret online in dynamic meaning construction. Our examples of humorous modified proverbs show that although jokes are verbalised in the form of proverbs, the humour is derived from the same mechanisms that are employed in other types of verbal humour: puns, play on words, metonymies, elements of surprise, exploitation of taboos, etc. The evidence for this is found in the fact that those modified proverbs that employ only some of these elements, or do not employ any of them, are found to be less humorous or not humorous at all.
\end{abstract}

Keywords: proverb creation and interpretation, cognitive mechanisms, the theory of conceptual integration, humorous effect, cultural settings.

\section{Introduction}

There is an undeniable link between culture and language. Among the many phenomena of language, one that reflects practical experience and values of humanity is its proverbs. A proverb is a simple and short, concrete, and often witty saying that successfully encapsulates a society's system of beliefs and values or expresses a truth based on common sense (Klaić 1962; Mieder 
1985). Both the Bible and Medieval Latin have played a considerable role in distributing proverbs across languages and cultures. Whether borrowed or original, every culture has examples of its own proverbs.

Proverbs are often metaphorical in nature and reveal the results of the experience gained by observation of everyday objects or, simply, laws of nature. One such example is the Welsh proverb "A seed hidden in the heart of an apple is an orchard invisible". Even though Croatian culture shares no such proverbial expression, it does not prevent us from interpreting it correctly. The process of interpretation of the meaning of a previously unknown proverb upon first encounter is one of the questions this paper attempts to answer. Just like the once invisible seed could potentially bloom into an orchard, so could an unknown proverbial expression hide a potentially universal wisdom. If the apple is the tree's way of getting us to spread its seeds, we have our passion for proverbial wisdom to thank for its distribution across languages and cultures. Which cognitive mechanisms and aspects of general knowledge should be employed in order to pick the right proverbial apple in the sea of other ripe fruits in the orchard is yet another issue to be examined in the paper.

Even though scrutinized by many researchers, as an ongoing phenomenon proverbs are still appealing to many linguists, sociologists, paremiologists, and other scientists who use them as a remarkable source of new findings. Among the different paremiological aspects under study we may encounter the following: relationship between traditional and innovative folklore, pragmatic effect, semantic relations, discourse analysis, etc. This paper investigates a range of applications and interpretations of the existing cognitive models in its attempt to show universality of cognitive mechanisms and humour in the creation and interpretation of proverbs across languages under study.

The aim of the present paper is to designate the cognitive mechanisms that are employed in the creation and interpretation of both traditional and modified proverbs in English and Croatian. The structure of the paper reflects the objectives under consideration. It will begin with a brief overview of our latest findings considering the pervasiveness of proverbs in English and Croatian public written texts. The cognitive approach to proverbs will be discussed next. After a brief theoretical assessment of the existing cognitive linguistic theories (The Theory of Conceptual Metaphor and Metonymy, Conceptual Integration Theory) and their correlation with humour, we will conduct a set of case studies to test if they can be universally applied to the selected proverbs in both languages. Finally, the paper draws concluding observations following from the questions under study, offering some insights into the fruitful interplay of phraseology, cognitive linguistics, and humour in creating and interpreting traditional and modified proverbs across languages and cultures.

\section{Proverb pervasiveness in public written texts}

Proverbs are miniature linguistic units, which schematise concrete experiences and convey general truths. However, they have never been considered absolute truths, which leaves room for modifying them to suit the particular context, or create an ironic or humorous effect.

Under the premise that they have been passed on from generation to generation primarily by word of mouth, we expected to find fewer of them in written contexts. However, traditional proverbs as well as their modifications seem to feature as an increasingly common rhetorical and stylistic device in written texts. 
Working on a corpus comprising of written texts (newspaper reports, comments, graffiti, etc.), our previous research (Molnar \& Vidaković Erdeljić 2009) has validated the presence of modified proverbs in both languages under study (see Table 1.). 194 proverbs were collected from randomly chosen Croatian daily papers (Vjesnik, Jutarnji list, Večernji list, Glas Slavonije, 24 sata) and English printed media (The New York Times, The Guardian, The Observer).

Table 1. Pervasiveness of proverbs in Croatian and English public written texts.

\begin{tabular}{|c|c|c|c|}
\hline & $\begin{array}{c}\text { TRADITIONAL } \\
\text { PROVERBS }\end{array}$ & $\begin{array}{l}\text { MODIFIED } \\
\text { PROVERBS }\end{array}$ & TOTAL \\
\hline $\begin{array}{c}\text { CROATIAN } \\
\text { CORPUS }\end{array}$ & $(38,95 \%)$ & $(61,05 \%)$ & 95 \\
\hline $\begin{array}{c}\text { ENGLISH } \\
\text { CORPUS }\end{array}$ & $(8,08 \%)$ & $(91,92 \%)$ & 99 \\
\hline
\end{tabular}

\section{Theoretical background}

\subsection{The cognitive approach}

Cognitive modelling should be seen as a theoretical approach based on the idea of the conceptual nature of semantic reinterpretation. Semantic reinterpretation taking place in the process of creating phraseological units is a result of the interaction of fairly sophisticated knowledge structures. Aside from being a wonderful pond of wisdom, proverbs seem to be products of our conceptual system as well. Since conceptual structures stand behind linguistic structures (cf. Talmy 2000), we will attempt to show how their interpretation rests upon the interplay of one or more cognitive mechanisms. In this paper we will examine the role of generic cognitive mechanisms in language structure through an analysis of both traditional and modified proverbs in Croatian and English. We will provide an outline of proverb cognition based on universal principles, which constitutes an alternative view to that of Lakoff \& Turner (1989), and is in line with Ruiz de Mendoza (1999: 54), who puts forward a more economical and motivated conceptual model. It allows proverb interpreters to use their knowledge of the specific scenario coded in the proverb to understand many analogical situations based on the same generic level structure. Thus, proverbs are mentally economical, since the one particular situation presented in them enables the understanding of many others.

\subsection{Questions under consideration}

Working on a corpus of Croatian and English proverbs and their modifications, we will primarily be looking for data supporting Lakoff \& Turner's account of proverbs (1989) and therefore attempt to answer the following questions: 
- Which cognitive mechanisms are employed in the creation and interpretation of proverbs in cases under study?

- Can generic is specific metaphor account for all the instances of traditional and modified proverbs?

- Can linguistic humour theories and cognitive linguistics provide an adequate framework and articulate tools for the analysis of modified proverbs?

- Which factors influence the level of humour in modified proverbs?

- Do differences present at the lexical level stem from different cultural settings and profiling?

\subsection{On metaphor and metonymy}

\subsubsection{Cognitive linguistic approach to metaphor}

The extensively quoted book - Metaphors We Live By - by Lakoff \& Johnson (1980), which was entirely dedicated to the metaphor, brought about an explosive outburst of interest in and research of metaphor. Traditionally considered as tropes and thought to belong primarily to poetry, metaphors are now viewed in a different light, i.e. not only as figures of speech but modes of thought. The same view became standard through the publication of The Body in the Mind (Johnson 1987) and Women, Fire, and Dangerous Things: What Categories Reveal about the Mind (Lakoff 1987). According to both authors, the major premise of cognitive linguistics is to explain the conceptual system and language through the study of the brain and the mind. Metaphors are thus described as conceptual devices used for understanding or creating reality, rather than describing it. Lakoff and Johnson continue by saying that:

The primary function of metaphor is to provide a partial understanding of one kind of experience in terms of another kind of experience. This may involve preexisting isolated similarities, the creation of new similarities, and more.

(Lakoff \& Johnson 1980: 154.)

In other words, metaphor is described as "understanding and experiencing one kind of thing in terms of another" (Lakoff \& Johnson 1980: 5). The basis of the Lakoffian theory of conceptual metaphors could be summarised as follows:

- Conceptual metaphors represent a set of mappings, i.e. systematic correspondences between two domains (more precisely, between the elements in two domains). According to Langacker (1987: 148) a domain is any coherent organisation of experience.

- Metaphor (see Figure 1.) is defined as understanding one conceptual domain (more abstract or target domain) in terms of another conceptual domain (more concrete physical domain or source domain). Target and source are the Lakoffian terminological counterparts for the traditional notion of metaphor tenor and metaphor vehicle.

There is, for example, a highly general metaphor human is animal, illustrated in the following proverbs: The early bird catches the worm. / Every dog has its day. / When the cat's away the mice will play. / Let sleeping dogs lie. / The leopard cannot change his spots.

A similar cognitive concept of metaphor was propounded by Barcelona (2000: 3). He defines metaphor as the cognitive mechanism, whereby one experiential domain (the source or 
donor domain) is partially mapped onto a different experiential domain (the target or recipient domain), the second domain being partially understood in terms of the first one. That means that some aspects of the source domain are hidden whereas others are emphasised. Both domains have to belong to different superordinate domains. Once a metaphoric mapping is established, we may say that the target domain has been metaphorically structured in accordance with the source domain. The high level of entrenchment in a speech community makes the language users mostly unaware of their existence. One of the important elements in metaphorical interpretations is property selection. It includes scanning all types of encyclopaedic, linguistic, and contextual considerations, resulting in property adjustment of all the elements of the source that are not applicable to the target. Such an adjustment does not only make metaphor a very expressive device, but it also allows us to use physical experience to create abstract notions.

In sum, metaphors are important cognitive tools primarily used for the purposes of understanding less clearly structured domains in terms of more clearly structured domains, in our attempt to comprehend the world around us.

\subsubsection{Cognitive linguistic approach to metonymy}

Much of the early research in cognitive linguistics was centred around metaphor and categorisation, leaving metonymy in a marginal position. In recent years, many linguists (Radden and Kövecses 1999; Barcelona 2003 [2000]) have shifted the focus of their research towards metonymy, claiming its rightly deserved position as a cognitive phenomenon that may be more fundamental than metaphor.

Traditional readers and dictionaries have defined metonymy as the substitution of one word for another on the basis of contiguity. In the Lakoffian theory, metonymy (see Figure 2.) is $A$ stands for $B$ relation within one and the same domain, that is, metonymies are based on two entities which are closely related to each other in conceptual space.

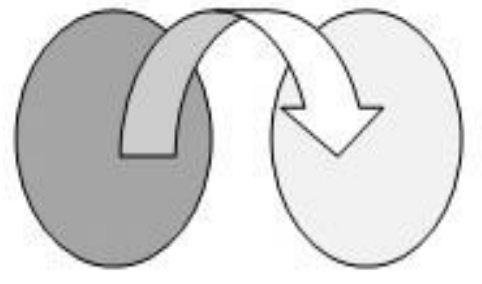

Figure 1. Metaphorical mapping.

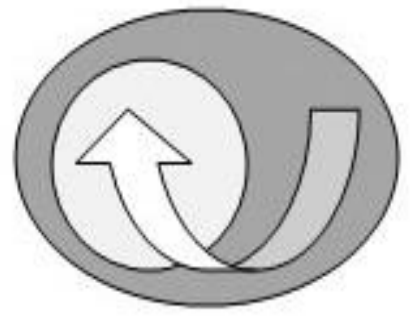

Figure 2. Metonymic mapping.

Lakoff \& Johnson (1980: 37) view metonymic concepts as part of the ordinary, everyday way we think and act as well as talk. Metonymy is a cognitive mechanism whereby one experiential domain is partially understood in terms of another experiential domain included in the same common experiential domain. Many linguists agree upon the mapping within a single conceptual cognitive unit, but term it differently: Lakoff (1987) and Lakoff \& Turner (1989) suggest domain, Croft (1993) domain matrix, Kövecses \& Radden (1998) and Radden \& Kövecses (1999) frame. Radden \& Kövecses (1999: 21) give the following definition of metonymy:

Metonymy is a cognitive process in which one conceptual entity, the vehicle, provides mental access to another conceptual entity, the target, within the same idealised cognitive model. 
According to cognitivists, metonymy may occur wherever we have idealised cognitive models. Idealised Cognitive Model (ICM) is defined as a relatively stable mental structure that represents an individual's knowledge and beliefs about a particular domain of experience, and guides categorisation and searching relative to that domain (Lakoff 1987). Thus, metonymy provides an effective mental access to a conceptual entity that need not be otherwise easily accessible (Kövecses \& Radden 1998; Radden \& Kövecses 1999). In other words, it offers a mental shortcut making it possible for us to refer to entities for which there are no convenient linguistic expressions.

Since our knowledge of the world is organised by structured ICMs, which we perceive in terms of wholes with parts, Radden \& Kövecses (1999) identify two general conceptual configurations:

1. Whole ICM and its part(s); this configuration gives rise to metonymies in which we access a part of an ICM via its whole or a whole ICM via one of its parts.

2. Parts of an ICM, which may lead to metonymies in which we access a part via another part of an ICM (the whole ICM is still implicitly present in the background).

The following examples illustrate one of the most common subtypes of the conceptual metonymy, that is, part for the whole metonymy: A false tongue will hardly speak the truth. I Beauty is in the eye of the beholder. / In one ear and out the other. / Scratch my back and I'll scratch yours. / Two heads are better than one.

Langacker (1993: 30) describes metonymy as follows:

A well-chosen metonymic expression lets us mention one entity that is salient and easily coded, and thereby evokes - essentially automatically - a target that is either of lesser interest or harder to name.

According to Langacker (1993: 30), metonymy is grounded in reference point constructions and due to their fundamental nature serves a communicative as well as cognitive function.

We may conclude that cognitive approaches to metonymy provide illuminating analyses of a range of metonymies, and shed light on the role of association in human conceptualisation and structuring the world around us.

\subsection{Humour in cognitive linguistics}

Despite the fact that humour is still a largely marginalised topic in the cognitive linguistics paradigm, some theoretical accounts (developed by Giora 1991, 2003; Veale 2004; Brône and Feyaerts 2004; Coulson 2001, 2006) provide a necessary background in the field, merging psychological models of humour with the major tenets of cognitive linguistics. Cognitive linguistics, with its focus on cross-cognitive and conceptual aspects of language use, should provide an adequate framework and articulate tools for the analysis of complex, creative, and dynamic phenomena in modified proverbs.

The relationship between humour and metaphor has not gone unnoticed: humorous interpretation of the figurative expressions often hinge on exploiting the salience gap between literal and figurative readings in the mind of the speakers involved. The duality and tension in bringing two concepts together, proposed by Koestler (1964: 51), lie at the very root of metaphor. The same idea of the two opposing scenarios (scripts) is also mentioned by Attardo 
(2001: 2), while the script itself is defined as "a cognitive structure internalised by the speaker which provides the speaker with information on how a given entity is structured".

According to some viewpoints (Tourangeau \& Sternberg 1981: 30), most humorous metaphors correlate positively with the dissimilarity between the concepts/domains. In other words, the distance and incongruity between the concepts/domains (i.e. the black sheep of the family) may be regarded as a characteristic feature of humorous metaphors. This incongruity can give rise to sub-types of metaphors, e.g. personification or 'animalification' as illustrated by many proverbial expressions. Incongruity resolution will be further exploited and elaborated in the analysis of modified proverbs (see Section 5.2.1).

\section{Proverb processing}

The Cognitive Theory of Metaphor proposed by Lakoff \& Johnson (1980) has been embraced as a significant tool for interpreting conventional phraseological units. However, some other scholars (Ruiz de Mendoza 1999; Díez 2000; Deane 1992) challenge this theory and argue that, although accounting for many examples, the knowledge of underlying conceptual metaphors is insufficient in particular cases. In addition to that, the theory primarily addresses the internal structure of the conceptual-metaphorical world itself, and not the processes of comprehension of figurative speech in actual verbal communication.

Most of our proverb cognition is based on universal principles, which constitutes an alternative view to that of Lakoff \& Turner (1989), and is in line of Ruiz de Mendoza (1999: 54), who puts forward a more economic and motivated conceptual model.

To account for a vast number of phraseological units, including traditional and modified proverbs, a fairly complex interplay of not only cognitive mechanisms (conceptual metaphor and metonymy, conceptual integration), but also our entire encyclopaedic knowledge, as well as knowledge of the language must be taken into consideration.

\section{Case studies: Cognitive analysis - from non-humorous traditional to humorous modified proverbs in English and Croatian}

The paper continues with a set of cross-linguistic case studies of both traditional and modified proverbs, in order to further inspect the presence of all the cognitive mechanisms and additional factors at work in proverb creation and interpretation. The first part of the section will focus on generic-level structure and conceptual interaction patterns in selected proverbs and their possible lexical equivalents across languages under study.

\subsection{Traditional proverbs}

Case study 1. 'Vrana vrani oči ne kopa' (Crow does not poke another crow's eye)

Let us begin with a Croatian proverb 'Vrana vrani oči ne kopa' (Crow does not poke another crow's eye) as a rather transparent example of a metaphorical mapping between animal as the source and people as the target domain (see Figure 3.). The meaning behind the proverb derives from our knowledge of birds and their behaviour on the one hand, and people and their 
relationships on the other. It is a well-known fact that birds get some protection from predators by being in a large group, just like people tend to socialise and protect the ones that belong to the same group. Bearing this in mind, birds, i.e. crows, serve as an excellent source domain in understanding human qualities and nature. Namely, 'animal 2' (in this case, 'a crow') is mapped onto 'person 2' (in this case 'any person' that belongs to a certain group/community and could be potentially harmed by 'another member of the group' ['person 1'], presumably closely related). The correspondence between the two domains reveals the same fundamental concept of personal relationships based on either blood, closeness, intimacy, similar character or interests in the form of metaphorical subtype intimacy is closeness.

\section{SOURCE METAPHOR TARGET}

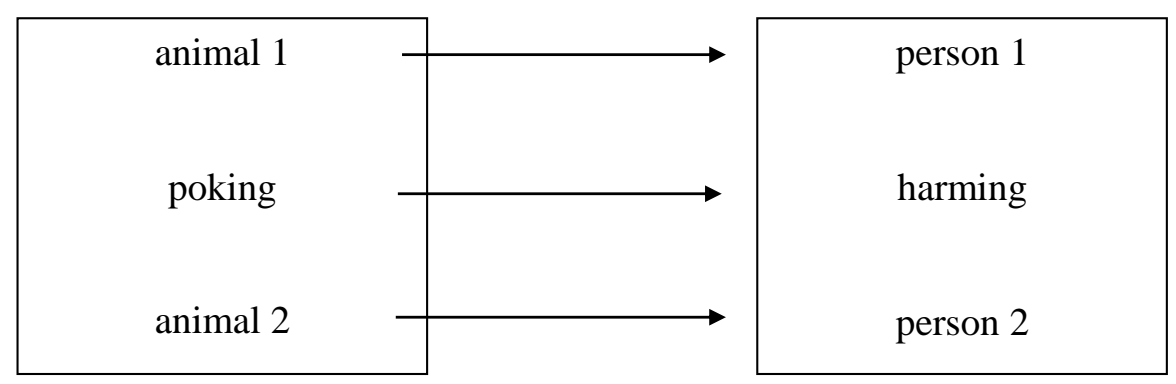

Figure 3. 'Vrana vrani oči ne kopa' (Crow does not poke out another crow's eye).

Case study 2. Don't bite the hand that feeds you

Let us now continue with the well-known traditional English proverb don't bite the hand that feeds you (see Figure 4.). The schema below (Díez Velasco, 2001-2: 55-56) illustrates the typical case of two cognitive mechanisms at work: metonymy and metaphor. The proverb is to be interpreted as a warning not to harm the person that helps you. The mappings take place between the corresponding elements of the two separate domains (source and target), and this is where metaphor takes place. Namely, 'animal' is mapped onto any person that hurts his protector and 'biting' onto any action that hurts. Within the source domain of this metaphor, there is a source-in-target metonymy where 'hand' stands for 'the feeder', that is 'the part' stands for 'the whole'. We can easily justify the choice of 'the hand' by using our general knowledge of the world, i.e. hand being the most salient body part in the process of feeding. By means of part for whole schema, we perceive entities around us as being composed of other entities. The interplay of both metonymy and metaphor contribute to the full interpretation of the proverb. 


\section{SOURCE METAPHOR TARGET}

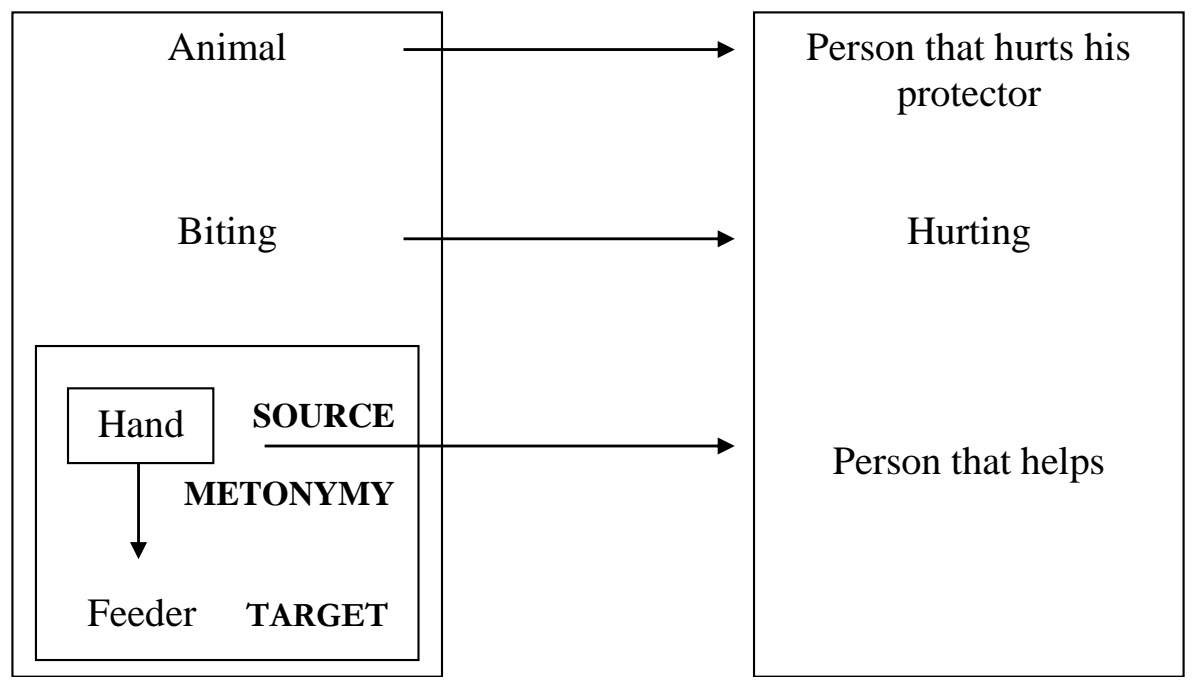

Figure 4. Don't bite the hand that feeds you. Metonymic expansion of one of the correspondences of a metaphoric source. $^{1}$

Case study 3: 'Ne sijeci granu na kojoj sjedišs' (Don't saw off the branch you are sitting on)

To see whether the same cognitive mechanisms are at work in Croatian language, let us now consider the proverb 'Ne sijeci granu na kojoj sjediš' (Don't saw off the branch you are sitting on) (see Figure 5.). In this particular case, 'cutter' is mapped onto 'any person that hurts his protector' and 'cutting' onto the action of 'harming' someone. Metonymic expansion within the metaphorical source includes 'branch', which stands for any kind of 'physical or mental support'. We may conclude that, in spite of a different lexical content, the Croatian proverb instantiates the same generic schema with equivalent illocutionary force. 
SOURCE METAPHOR TARGET

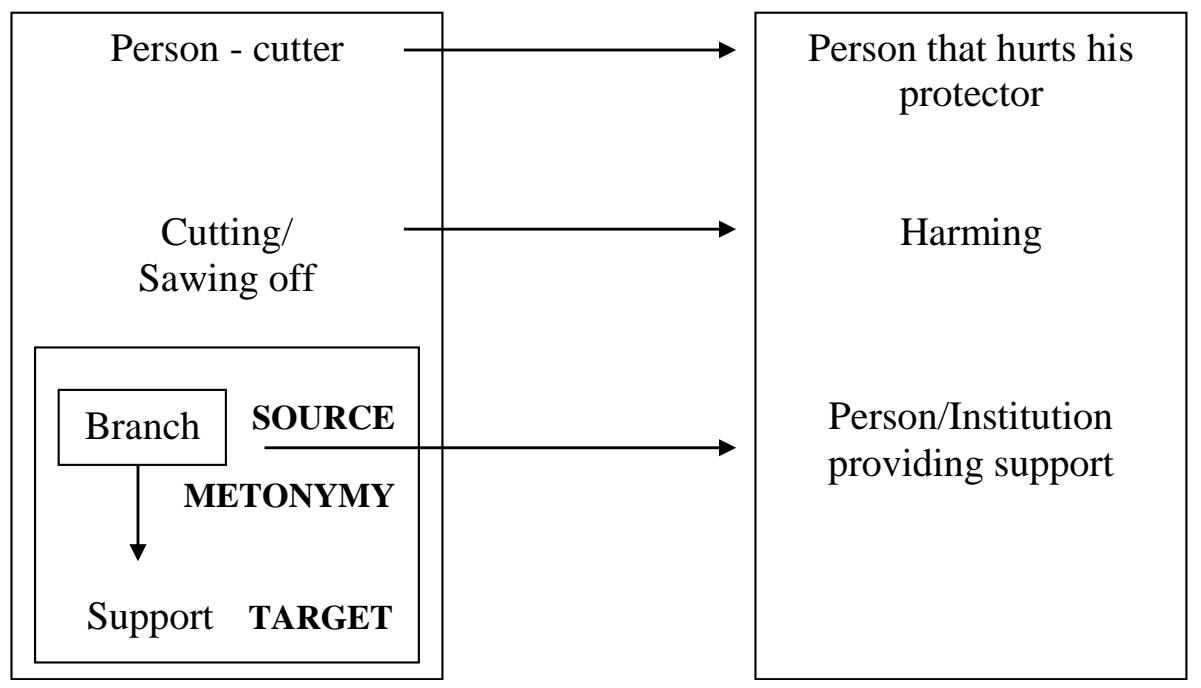

Figure 5. 'Ne sijeci granu na kojoj sjediš' (Don't saw off the branch you are sitting on)

Case study 4: Leopard does not change his spots ('Vuk dlaku mijenja, ali ćud ne')

The proverb leopard does not change his spots reveals the same interactional patterns between metaphor and metonymy as in the Case studies 2 and 3. On closer examination, we may notice a fruitful interplay of a conceptual metaphor people are animals and metonymic subtype salient physical feature for salient emotional feature (see Figure 6.). The proverb is to be interpreted as a warning not to assume that people's change of appearance will ultimately lead to the change of their innate nature. In this particular case, 'leopard' is mapped onto 'a person' that tends to maintain some aspects of his/her character. Metonymic expansion within the metaphorical source includes 'spots' which stand for the innate and permanent part of the leopard's whole physical appearance. In other words, the metonymy highlights the important of spots as the most prominent aspect of leopard's overall physical traits.

Croatian language lexicalises the same concept with a different proverbial expression ' $V u k$ dlaku mijenja, ali ćud ne' (lit. the wolf changes its hair, but not its character). The choice of 'a wolf' rather than 'a leopard' seems justifiable and is governed by the cultural and environmental setting and the way we perceive animals. Our folk understanding of what these animals are like is metaphorical and helps us understand human qualities and nature. We may conclude that the same cognitive mechanisms are at work in both proverbs. In spite of a different lexical content, the Croatian proverb instantiates the same generic schema with equivalent illocutionary force. Thus, even if the proverbs are unfamiliar or heard for the first time, we can easily understand the moral of both of them. 
SOURCE METAPHOR TARGET

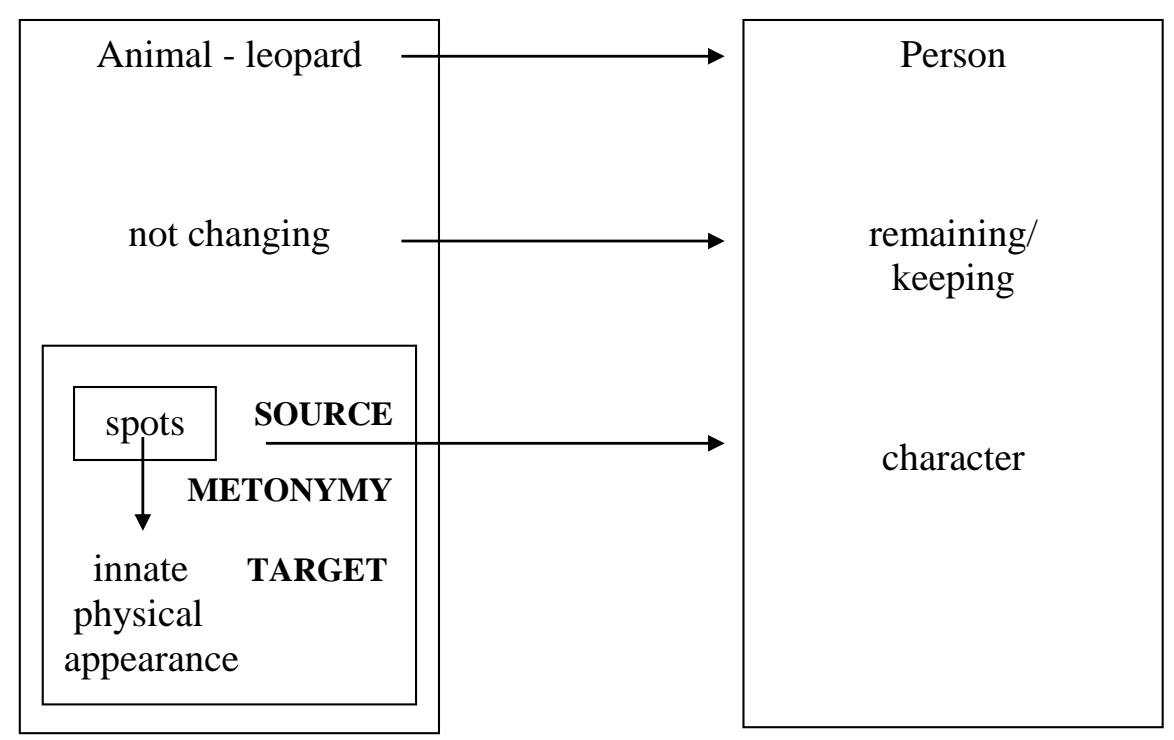

Figure 6. Leopard does not change its spots. Metonymic expansion of one of the correspondences of a metaphoric source.

Case study 5: There is a black sheep in every flock

Let us now consider another canonical English proverb there is a black sheep in every flock. It is a prototypical example of the well-known opposition between the purity and goodness of the divine light, and the evil and impurity of the dark. Its origin could be traced back to the story of Genesis, but it has successfully found its way into many European languages today. Even though the origin of the proverb does not necessarily evoke negative associations of the 'black sheep', the prototypical meaning that prevails nowadays definitely points to qualities such as 'evil', 'bad', 'different', 'odd'. Traditionally, the actual meaning of this proverb would be interpreted as applying relevant semantic features of the black sheep taken literally to a person. In cognitive modelling, the proper interpretation would rely on the fruitful interplay of cognitive mechanisms, our knowledge of colour semantics, and knowledge of the world.

Figure 7. below is an attempt to illustrate a simplified and quite transparent representation of meaning, fully in line with Langacker's (1987: 165-166) open-ended view consisting of networks and activated nodes instead of static structures. Let us now briefly explain the conceptual structure of attributes and primary domain. It is important to mention that the figure itself is a simplified version of the conceptual structure and by no means should be interpreted literally. The dotted line surrounding the structure indicates that it is not possible to draw a strict line between the important and less important attributes while defining a concept. The primary domain, against which the most relevant facts about the concept are defined, takes the central position. The attributes, in the form of octagons, differ in their distance from the centre, and, accordingly, in their importance. Contextual environment may easily contribute to the change of the attribute structure, allowing some peripheral attributes to become more central. For the sake of clarity and simplification, the concept is divided into two halves, whereas the attributes are presented symmetrically. This by no means implies a sharp division of the concept into the 
concrete and the abstract one (due to the fact that abstract concepts are grounded in some kind of physical experience), just like there is no apparent symmetry in the attribute structure.

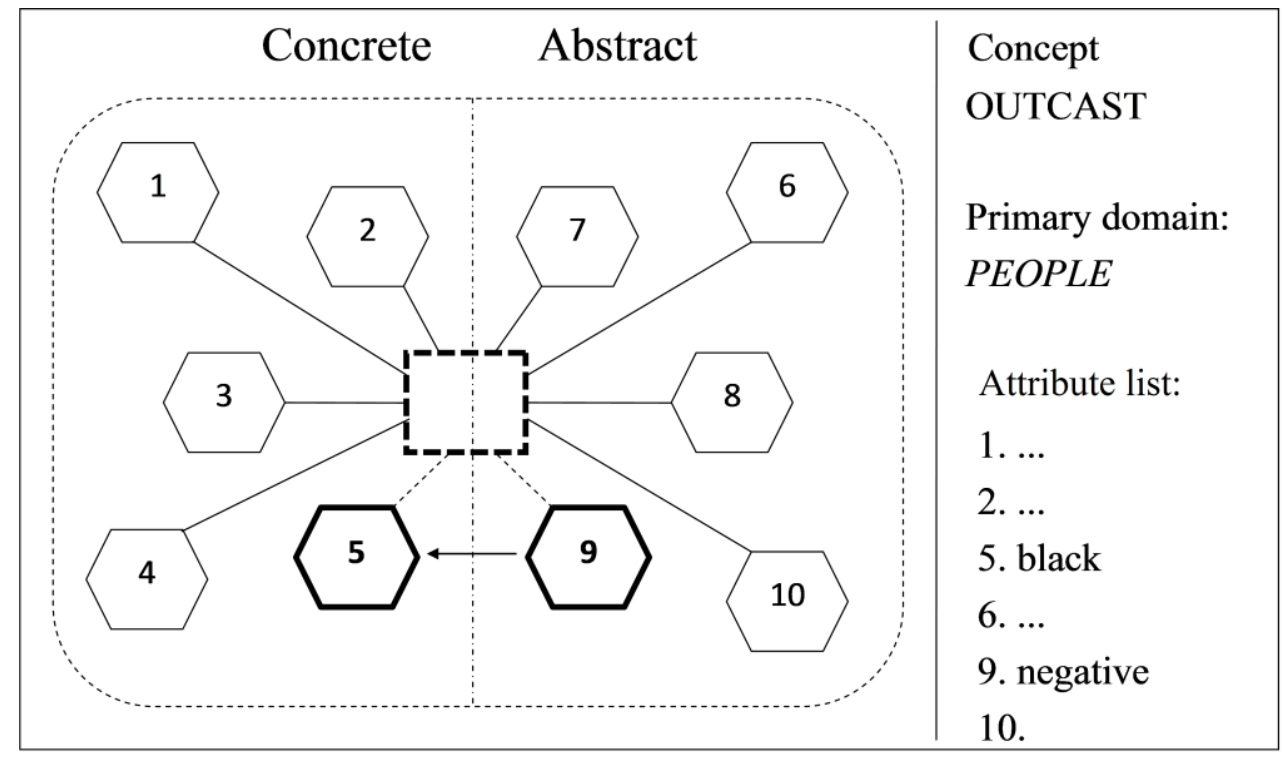

Figure 7. Black as 'negative' in the formative domain of outcast.

Let us see which cognitive mechanisms motivate the interpretation of the above mentioned proverb. All the members of a given linguistic community share the same knowledge that words meaning black have a secondary reading, which can be universally described as 'odd', 'evil', 'bad'. Due to the cultural link between the colour black and the concepts of negative values, the function of black serves some further purpose other than merely ascribing a colour to the noun. Since there is nothing distinctive about the animal's behaviour, the colour term itself triggers the sense of 'evil', 'bad', 'negative'. Therefore, the proverb might be considered a proper instance of figurative usage of a colour term.

Aside from a highly general metaphor human is animal, where a 'black sheep' is mapped onto a 'person judged to be bad/odd/undesirable', and 'every flock' onto 'any relevant group of people' (presumably 'family'), we have also identified metonymy of the type salient concrete attribute stands for salient abstract attribute. The abstract attribute negative is directly associated with the concrete attribute black, which is a salient feature in the domain of outcast. Naturally, 'sheep' should be metaphorically interpreted as 'people', but the focus of the conceptual structure in Figure 7. is the colour term. It is important to stress that the generic level schema is preserved: there is no evidence of anyone being described as the 'black sheep' of anything other than a more or less standard group of people or some kind of community.

Although the proverb has a full equivalent translation in Croatian ('crna ovca u obitelji'), there is a different lexical realisation ('U svakom žitu ima kukolja' - lit. every corn has its weed) of the same concept. English language, in turn, offers additional lexicalisation of the second Croatian concept in the form of the following proverb: every barrel has its bad apples. The similar opposition between the positive and negative, between good and bad, is represented in 
yet another English proverb: every rose has its thorns. Unlike the previously mentioned proverbs, which are related to the image schema of containment, the last one is based on the whole-part image schema, and normally used in a different context.

To sum up, the retrieved data from both languages support the high frequency of two natural source domains in the traditional proverbs: zoology (sheep, leopard, crow) and botany (corn, weed, branch).

Lakoff's (1989) The Great Chain Metaphor allows us to interpret many different situations with the same generic-level structure. As the analysis has shown, the source domain of the people are animals metaphor is developed through a source-in-target metonymy. This metonymy structures a mental space to make the mapping from a specific to any generic situation that will be the source domain - or part of it - of the metaphor. In such a way, the role of metonymy is to highlight whatever is relevant to our understanding of the metaphorical mapping. In order to fully interpret the meaning of the proverb and to evoke the appropriate generic structure, all the correspondences from both source and target domain must be taken into consideration.

Additional theoretical support for the interpretation of cognitive processes which underlie such phenomena is to be found in Ruiz de Mendoza's Extended Invariance Principle (1998). What Ruiz de Mendoza (1998: 265) proposes is the convergence between generic is specific and people are animals metaphor with any ICM arguing that "[A]ll contextual effects motivated by a metaphoric mapping will preserve the generic-level structure of the source domain and of any other input space involved, in a way consistent with the inherent structure of the target domain." Which out of many aspects of the source domain will take preference in a given language is almost impossible to predict, but the final entrenchment of the lexical expression will definitely depend on the salient cultural setting and profiling. The fact that many proverbs coincide, if not in the form and the perspective, at least in the moral values they propose, speaks in favour of their universality.

\subsubsection{Absence of humour in traditional proverbs}

Bearing in mind that traditional proverbs serve mainly as the effective instrument for transmitting moral values, culture, manners, and ideas, it seems unnecessary to recognise humour in them. As the analysis above has shown, none of the traditional proverbs contributes to the humorous effect, nor is it their primary function. They might take the form of the aphorism, but the content of the traditional proverb is usually serious. Decontextualised examples of traditional proverbs serve rather as the basis of the incongruity resolution process in the interpretation of modified proverbs, which are much more dynamic, contextualised, and humorous by nature. The next section will be dealing with such novel, more of less humorous creations, analysed through the lens of conceptual integration theory.

\subsection{Traditional vs. modified proverbs}

So far we have dealt with traditional proverbs, whereas the present section will pay closer attention to humorous modified proverbs. The major difference between them is the fact that traditional proverbs, unlike modified ones, are conventional, they are stored in our long-term memory and when needed, let's say for the purpose of argumentation, we retrieve them with ease. Modified proverbs, on the other hand, are novel creations, expressions we produce online for the purpose at hand. Is it possible then to analyse such different, and yet so similar, phenomena by exploiting the same tools? 
Traditional proverbs resemble dead metaphors in many ways. For example, when a person hears something like I am feeling up today, s/he automatically knows that up in this statement does not refer to vertical extension in space but to happiness without for a moment being aware of the underlying metaphor. Very similar to this, if a person uses the proverb a leopard doesn't change its spots to make a point in a conversation, it is not for a moment again that we think that the speaker is actually referring to leopards. So both metaphors, i.e. happy is up and people are animals in the previous two statements are so well-entrenched and conventionalised that in our daily conversations they go unnoticed - they are dead for we fail to recognise them.

On the other hand, when a modified proverb is uttered, as we will see later, we immediately notice that something is out of the ordinary and eventually become aware of the underlying metaphor, which thus comes to life.

Although proverbs, when used alone, without a context, convey a complete message and, in this respect, are self-sufficient, they are nevertheless rarely used without a context where they serve numerous functions, among others, for example, to strengthen one's conclusions in the line of argumentation.

Lakoff \& Turner (1989) argue that proverbs activate schemas rich in images in our mind, along with our knowledge of the world and common day-to-day experiences. According to them, it is the generic is specific metaphor which allows us to understand a whole category of situations in terms of one particular situation. We, namely, extract the generic level schema from a single specific situation and then this specific-level schema is by way of generic is specific metaphor mapped onto an indefinitely large number of parallel specific level schemas, which all have the same generic-level structure as the source-domain schema. In other words, the generic level schema abstracts what is common to specific-level schemas, which are related by similarity (see Figure 8.).

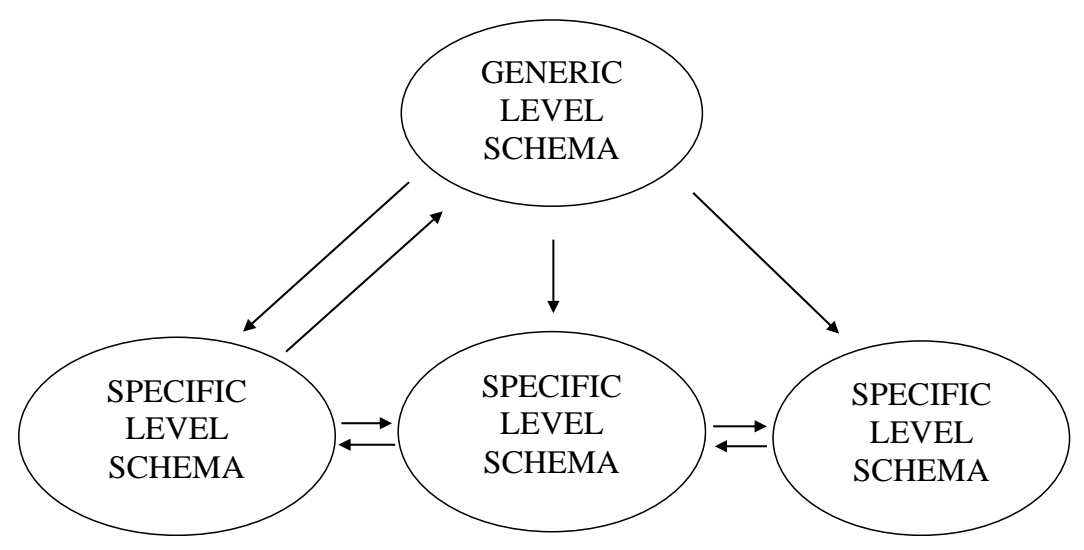

Figure 8. GENERIC IS SPECIFIC metaphor.

Proverbs evoke schemas rich in images and information: they evoke knowledge of common animals, objects, and situations. These schemas, which we referred to (...) as 'specific level schemas', include 
not only generic level information such as causal relations and shapes of events but also specific details and concrete images.

(Lakoff \& Turner 1989: 162.)

So when, for example, we comment on someone's behaviour by using the proverb leopard doesn't change its spots, it is because we recognise the generic schema of that proverb, i.e. the constancy of someone's character, in a specific situation and use the proverb to lend to our line of argumentation the authority of numerous generations who by using the proverb and keeping it alive have proved it right. We have two domains (Langacker 1987: 148), two stable knowledge structures that are stored in our long-term memory that are compared, the domain of animals and the domain of humans.

The generic is specific metaphor helps us understand modified proverbs as well, but although indispensable, alone it is not enough to account for such occurrences. We will need to resort to another cognitive mechanism - conceptual integration - the notion introduced in cognitive linguistics by Fauconnier and Turner (1994, 1999 and elsewhere). The crucial aspect of the theory of conceptual integration is that meaning construction involves emergent structure: meaning that is more than the sum of its component parts. They schematically model the process of conceptual integration by way of an integration network. They suggest that this network consists of inputs - temporary structures, i.e. mental spaces created during dynamic meaning construction. The elements of inputs are linked by mappings. Two (or more) input spaces are also linked by means of a generic space which contains information which is common to both (or all) inputs. The generic space that we have here corresponds to generic level schemas, whereas inputs correspond to specific level schemas of the generic is specific metaphor. The last element of an integration network is the blended space or blend which contains new or emergent structure, i.e. information that is not present in any of the inputs.

We find this theory particularly convenient for the interpretation of humorous modified proverbs since it concentrates on the dynamic meaning construction and temporary mental spaces. So, the essential difference between traditional, conventional proverbs on the one hand and modified proverbs on the other hand is that traditional proverbs rest on stable knowledge structures whereas modified proverbs rest on temporary mental structures created during dynamic meaning construction.

In what follows we provide several case studies in which we analyse modified proverbs in the light of the theory of conceptual integration. We will also compare several modified proverbs in an attempt to establish what adds to the humorous effect and why we find some modified proverbs funnier than some others.

\subsubsection{Humorous modified proverbs in light of the theory of conceptual integration}

Humorous modified proverbs combine the comfort of the known, safe and familiar, presented in the traditional proverb, with the pleasure and satisfaction we derive from being able to decode the meaning of the new, which is found in the modification. As we will see below, this resolvable incongruity, the clever balance between the old and the new, just like in other types of humour manifestation (Dynel 2009: 27) forms the cornerstone of a successful joke. Incongruity here is found primarily in the mismatch between the wording of the modified proverb and that of the conventional one, which is what attracts our attention, awakens our natural curiosity and compels us to go deeper and discover what lies behind it. 
As we argued earlier, the theory of conceptual integration is a suitable tool for analysing novel, creative expressions that do not exist in our memory since it tends to explain what goes on in the process of dynamic meaning construction. We will analyse several examples of modified proverbs in English and Croatian in light of the theory of conceptual integration and try to answer how this theory can account for the humorous effect. We also argue that the theory of conceptual integration, when applied in the analysis of humorous verbalisations, complements the incongruity and resolution theory of humour espoused by many authors (Schulz 1974; Suls 1983), which basically states that a certain resolution information cannot be detected until the incongruity is resolved.

We also argue that the presence of other cognitive mechanisms, of metonymy primarily, adds to the humorous effect because it requires the hearer to put more effort into the resolution process, which eventually makes the solution more rewarding.

The examples analysed in the following section have been collected in the course of our research on proverbs in English and Croatian from different newspapers or were retrieved from the Internet.

\section{Case study 6: Birds of a feather flock together before they drop off the twig}

The first example that we will analyse is the proverb birds of a feather flock together before they drop off the twig. As is often the case with modified proverbs, its true humorous potential can only be appreciated if we view it against the context in which it was produced. This particular one was the newspaper headline of an article about care homes for retired members of specific professions - in the case at hand journalists and their dependants, who hoped that even after retiring they would be able to talk shop with people with whom they shared common interests.

The integration network modelling the resolution of this modified proverb actually consists of two integration (sub)networks which need to be disentangled in order to access the humour. In the first network we view the traditional proverb against the specific context to which it applies. The proverb - birds of a feather flock together - features as the first input, one already present in our conceptual system. The second input is the specific situation in which the author of the headline recognises similarities with the familiar proverb - retired members of a specific profession who prefer spending time with people of their profession rather than people with whom they have no common interests. The elements of the proverb, input space 1, are mapped onto corresponding elements of the specific situation, input space 2 . These common elements are then projected in the generic space, i.e. the equivalent of the generic level schema. The generic level schema contains the following information: those who share common features are attracted to each other, tend to spend time together and consequently share the same physical space. In the blended space we combine the two inputs and arrive at a conclusion that people of the same profession like to live together as a community (see Table 2.). 
Table 2. Birds of a feather flock together.

\begin{tabular}{|c|c|c|c|}
\hline INPUT SPACE 1 & INPUT SPACE 2 & GENERIC SPACE & BLEND \\
\hline $\begin{array}{c}\text { Birds of the same } \\
\text { species tend to live in } \\
\text { colonies }\end{array}$ & $\begin{array}{c}\text { People of the same } \\
\text { profession like to } \\
\text { spend time together }\end{array}$ & $\begin{array}{c}\text { Those who share } \\
\text { some feature like to } \\
\text { share the physical } \\
\text { space }\end{array}$ & $\begin{array}{c}\text { People of the same } \\
\text { profession like to live } \\
\text { in colonies }\end{array}$ \\
\hline
\end{tabular}

We then proceed to the second part of the headline where we have an interesting play of words - the phrase to drop off the twig, which is crucial for the resolution of the incongruity present in this humorous verbalisation (see Table 3.). The phrase forces us again to access two different mental spaces: that of birds living in a colony and old people living in a retirement home. The verb drop off is polysemic and it can mean both fall off some elevated surface and fall asleep, but most importantly it is also highly reminiscent of the colloquial expression to drop dead. In the network illustrative of what goes on in the process of conceptual integration we have input 1 containing birds of the same species perching on a branch until the moment they die and fall off the twig, and in input space 2 we have old people hanging out in a retirement home until one of them dies. What is common to these two mental spaces, i.e. what forms the generic space are agents sitting somewhere enjoying each other's company until the moment they die. The humour is resolved in the emergent, blended space where we have humans perching on a branch until the moment they die and fall off the twig. The pun present in the verb drop off is crucial for the humour here because it provides the access to two input spaces involved in the process of conceptual integration. Only when the hearer unpacks these input spaces is he able to construct the blend, resolve the incongruity and thus fully appreciate the humour intended.

Another issue in this specific instance that adds to the humour is the employment of the concept of death. Death is something rather usual in the context of retirement homes, but is also a taboo and this brave exploitation of a taboo in an unexpected context underlined by the ambiguity of drop off makes for a very clever and witty modification of a traditional proverb.

Table 3. Birds of a feather flock together before they drop off the twig.

\begin{tabular}{|c|c|c|c|}
\hline INPUT SPACE 1 & INPUT SPACE 2 & GENERIC SPACE & BLEND \\
\hline $\begin{array}{c}\text { Birds perching on a } \\
\text { branch until they fall } \\
\text { off of it }\end{array}$ & $\begin{array}{c}\text { Old people hanging } \\
\text { out with their friends } \\
\text { until they die }\end{array}$ & $\begin{array}{c}\text { Agents spend time } \\
\text { together until this } \\
\text { abruptly ends due to } \\
\text { an accident }\end{array}$ & $\begin{array}{c}\text { Old people perching } \\
\text { on a branch until they } \\
\text { die }\end{array}$ \\
\hline
\end{tabular}

Case study 7: A ring on the hand is worth ten on the phone

The modified proverb we consider next is actually an aphorism retrieved through Google search engine, which can be analysed and interpreted without the context just like traditional proverbs. This particular string of words reminds the hearer of the well-known proverb $a$ bird in hand is worth two in the bush, and thus the first incongruity, the lexical one, is solved. We are actually presented with the blend in the modified proverb and need to establish the input spaces and the generic space. Input space 1 is the traditional proverb, which also indicates the content of 
the generic space: it is better to have less of what is a certain gain than more of what is a potential gain. We still miss the input space 2, and the access thereto is provided when we solve the incongruity present in the pun of the ring, which points us to two mental spaces, that of engagement rings and that of telephone calls. These basically present our general knowledge, the context of the modified proverb, which is actually the input space 2 . However, we cannot appreciate the full potential of the humour of this modified proverb until we go a step further and unpack the metonymy we have here and which substantially increases the humorous appeal of the proverb. A ring on the hand, namely, is an instance of the metonymy of the type part of the scenario for the whole scenario, and stands for the marriage proposal, while rings on the phone evoke a scene in which a woman receives several phone calls from several suitors who do not offer the real ring. Again the generic space abstracts what is common to two input spaces: better to have less of what is a certain gain than more of what is a potential gain (see Figure 9.).

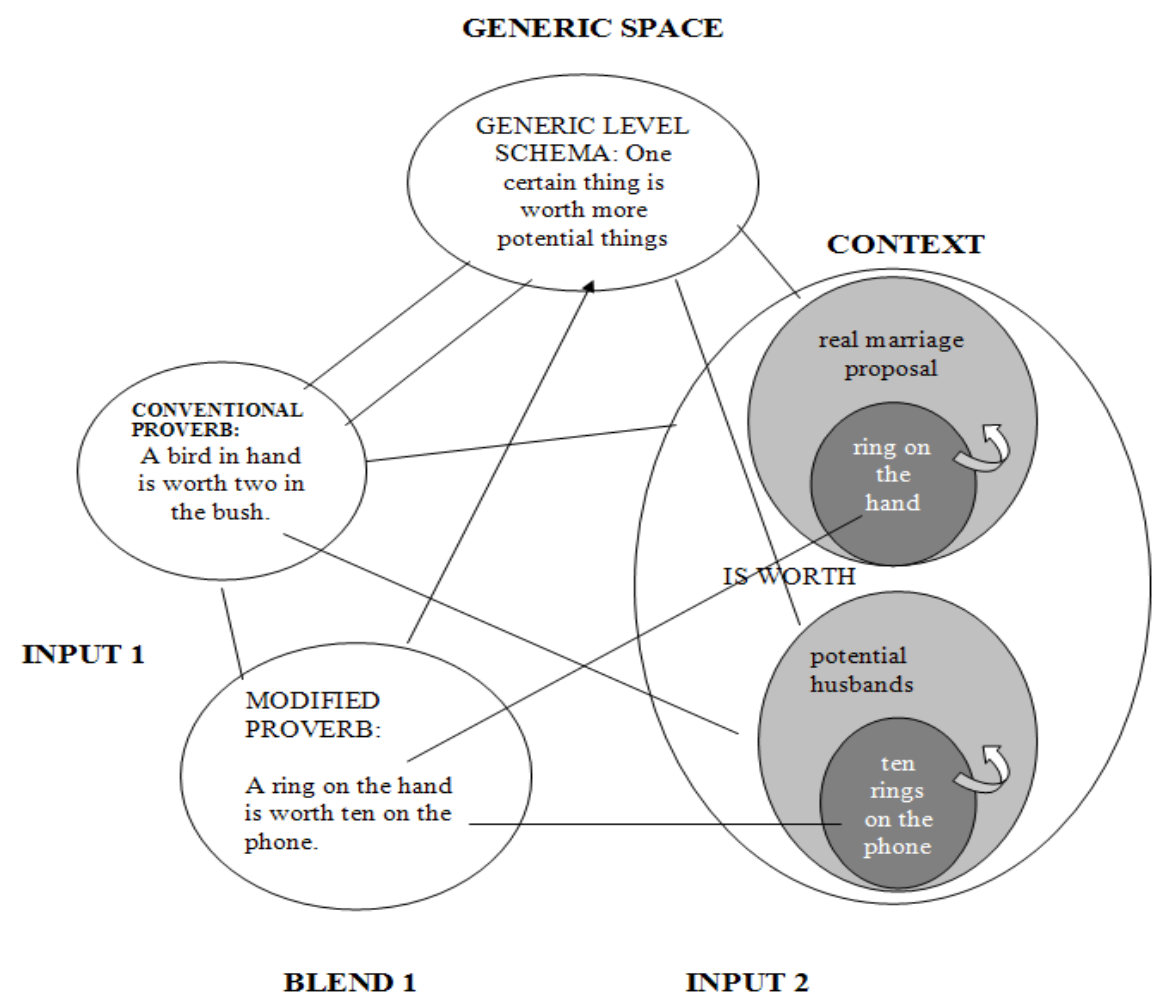

Figure 9. A ring on the hand is worth ten on the phone.

Concepts of less and more in less of what is a certain gain and more of what is a potential gain respectively are correct here only with regard to the surface level, i.e. the quantity. Based on our general knowledge of women whose ambition is to marry, we know that the real, ultimate gain is a husband, i.e. one ring on the hand - humour therefore emerges also from stating the obvious in an unusual way.

We also have something similar in the following example of a modified proverb a hair in the head is worth two in the brush. By stating the obvious and by seemingly attaching the label of less gain to something we value more, we manage to add humour to the saying. Helpful as always is also the pun at the lexical level which may, as is the case here, or may not designate the same concept, and which opens up two mental spaces and resolves the incongruity. 
Case study 8: 'Bolje šljiva u ruci nego na oku' (lit. a plum in the hand is better than a plum on the eye [i.e. black eye])

In the following part of this section we will analyse some Croatian modified humorous proverbs, which share the generic structure of the English proverb analysed in Case study 2 . The original Croatian proverb is as follows: 'bolje vrabac u ruci nego golub na grani' (lit. a sparrow in the hand is better than a pigeon on the branch). It is obvious that it roughly shares the same generic structure with the English proverb a bird in hand is worth two in the bush: a certain thing of lower value is better than a potential thing of higher value. The modified proverb 'bolje šljiva u ruci nego na oku' (lit. a plum in the hand is better than a plum on the eye [i.e. black eye]) that we will analyse here is again the result of a blend containing the grammatical structure of the input space 1 (the original proverb) and lexical items of the input space 2, which is provided by our general knowledge (see Table 4.). Actually, the hearer starts from the blend and immediately recognises the traditional proverb - the input space 1, which in a way entails what should be the generic space: a certain gain of a thing of lower value is better than a potential gain of a thing of higher value. However, for a brief moment the hearer encounters an incongruity, because in both parts of the modified proverb at the lexical level we have the noun 'šljiva' (plum) - the item of equal value, unlike the traditional proverb in which we have two things of different value. This forces us to cancel the generic space and look further for the meaning. It is hidden in the ambiguity of 'šljiva', and the hearer needs to disambiguate the polysemy of this word, which can denote both a type of fruit (plum) and - via similarity based on colour - a physical wound, i.e. black eye. On doing so he is able to access two mental spaces, which together form our general knowledge of the world, of plums and black eyes - the input space 2 . The humour consists in the clash between two senses of 'šljiva' which are activated simultaneously. So the message of the modified proverb is not some higher truth about modesty and about being reasonable in one's wishes as is the case with the traditional proverb. No, the modified proverb states what is obvious - it is better to have fruit than to have your physical appearance ruined by the black eye. Although it is verbalised through a proverb, the humour is actually achieved primarily through the pun. However, the surprise involved in the fact that when we hear a proverb we expect some clever and moral message and end up with something so plain and obvious, probably increases the humorous effect.

What is another advantage in this modification, which additionally emphasises the humour it contains, is the fact that both parts of the modified proverb are placed within the same knowledge domain - that of the human body.

Table 4. 'Bolje šljiva u ruci nego na oku' (a plum in the hand is better than a plum on the eye)

\begin{tabular}{|c|c|c|c|}
\hline BLEND & GENERIC SPACE & INPUT SPACE 1 & INPUT SPACE 2 \\
\hline $\begin{array}{c}\text { 'Bolje šljiva u ruci } \\
\text { nego na oku' (lit. a } \\
\text { plum in the hand is } \\
\text { better than a plum on } \\
\text { the eye [i.e. black } \\
\text { eye]) }\end{array}$ & $\begin{array}{l}\text { A certain thing of } \\
\text { lower value is better } \\
\text { than a potential thing } \\
\text { of higher value }\end{array}$ & Traditional proverb & $\begin{array}{l}\text { Knowledge of plums } \\
\text { and black eyes }\end{array}$ \\
\hline
\end{tabular}


Case study 9: 'Bolje šećer u škartocu nego u krvi' (lit. better to have sugar in a small paper bag than to have sugar in one's blood)

The next example of a modified proverb in Croatian, 'bolje šećer u škartocu nego u krvi' (lit. better to have sugar in a small paper bag than to have sugar in one's blood, i.e. a high level of glucose in one's blood) also shares the generic structure of the traditional proverb 'bolje vrabac u ruci nego golub na grani' (lit. a sparrow in the hand is better than a pigeon on the branch). The situation here is very similar to what we have had in the previous case study. The string of words of this modified proverb, which is the blend that the hearer needs to interpret, invokes the traditional proverb which forms the input space 1 . This in turn invokes the generic space containing the generic level schema of the traditional proverb: a certain thing of lower value is better than a potential thing of higher value. However, the mismatch between the blend, which at first glance compares two things of equal value on the one hand, and the generic space on the other hand, signals the incongruity. The incongruity can be resolved and the humour appreciated only when we solve the polysemy of the noun 'šećer' which provides us with the access to two mental spaces: that of sugar as an item of food, and that of sugar as the level of glucose, and the consequences of its overuse that indicate ill health. Again, although the humour here is verbalised as a proverb, all the fun resides in the pun, which opens up two mental spaces and resolves the blend.

Case study 10: 'Bolje jedna dama u krilu, nego dvije dame u pokeru' (lit. better to have one lady in the lap than two ladies in the game of poker, or, a queen in lap is worth two in the game of poker)

The last modified proverb that we analyse in this section is 'bolje jedna dama u krilu nego dvije dame u pokeru' (lit. better to have one lady in the lap than two ladies in the game of poker, or, a queen in lap is worth two in the game of poker). It is interesting because it does not entirely follow the structure of the Croatian traditional proverb 'bolje vrabac u ruci, nego golub na grani' (lit. a sparrow in the hand is better than a pigeon on the branch) and it actually may be the product of the contact between English and Croatian, since in its structure it is reminiscent of the English proverb a bird in hand is worth two in the bush, which shares the same generic level schema with the Croatian traditional proverb. Anyhow, the first incongruity encountered is the lexical one, which is solved once the blend is disintegrated into the original proverb. The original proverb accounts for the input space 1 and the expected generic space, which should contain information shared by two input spaces: a certain gain is better than a potential gain. The hearer then proceeds to interpret the input space 2. It represents the general knowledge of the world and starts with the pun involved in the noun 'dama', which can designate both a female person and a good card in the game of poker. This word provides the clue that leads us to two mental spaces that of cards and that of adult entertainment. We also have the metonymy of the type part of a scenario for the entire scenario in the fact that 'dama u krilu' (queen in the lap) stands for sexual pleasure, whereas 'dvije dame u pokeru' (two queens in the game of poker) stand for favourable cards in the game of poker (see Figure 10.).

The recognition of the discrepancy between the original and the modified proverb can fail to produce the expected generic space. Namely, the first part of the original proverb is used to denote a lesser gain, whereas in the modified proverb what men value as one of the ultimate pleasures - i.e. lap dance disguised in the phrase 'dama u krilu' and all the sexual connotations it 
carries - is found in this position. This is opposed to two winnings in the game of poker, which, although suggesting a lesser gain, are represented as something rather rare and more appealing, and unlike in the original proverb, appear in the second part of the modified proverb. Again this surprise increases the humorous effect.

Once again, although the humour is set within the framework of a proverb, all the fun is due to the pun, which opens up two mental spaces and allows the hearer to balance between two possible interpretations of the polysemic word, and thus fully appreciate the humour intended. The presence and humorous contribution of the metonymy should not be neglected either. It makes the joke slightly more difficult to interpret, but this effort makes the final result - the interpretation of the joke - all the more rewarding.

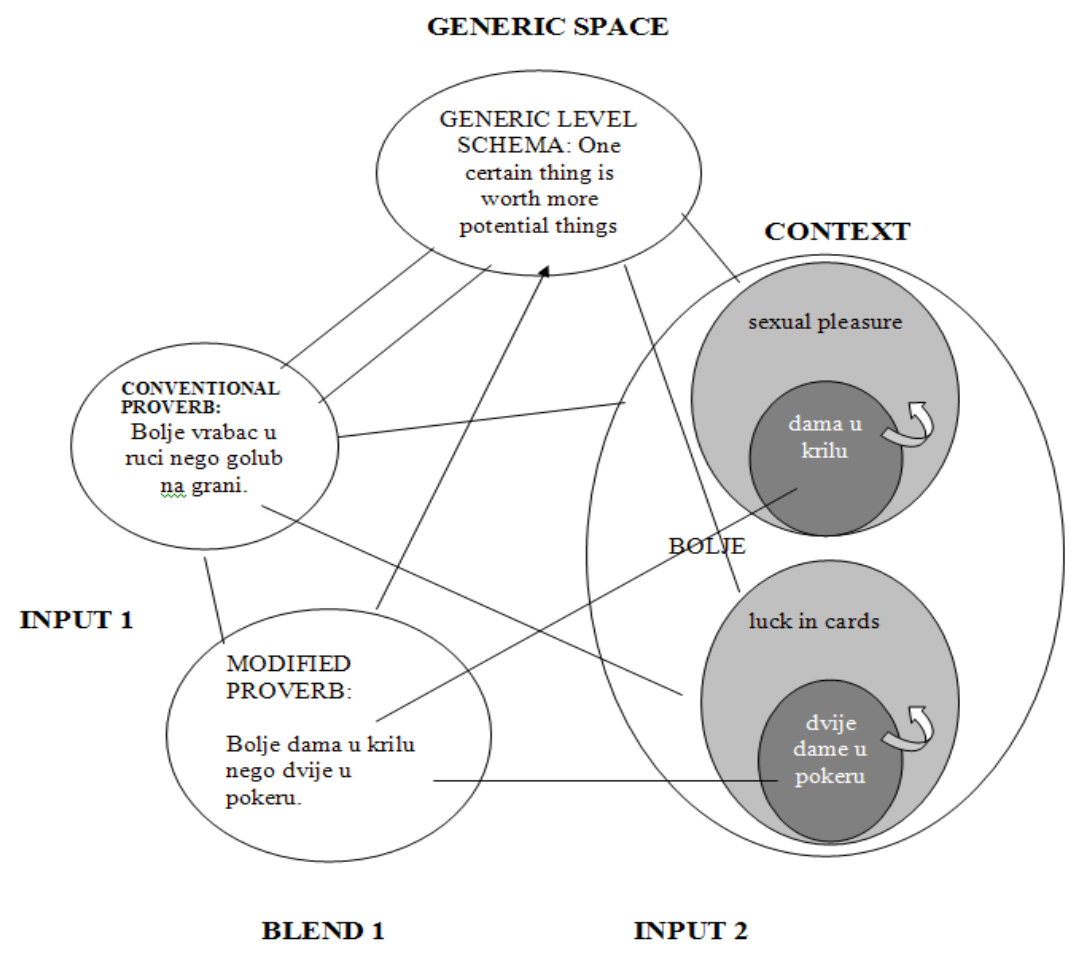

Figure 10. 'Bolje jedna dama u krilu, nego dvije dame u pokeru'

\subsubsection{Graded humour of modified proverbs}

In the previous section we have analysed humorous modified proverbs in light of the theory of conceptual integration. In the present section we will try to answer why certain modified proverbs are more successful than other with regard to the humorous effect they produce.

We will continue analysing modified proverbs, which rest on the original Croatian proverb 'bolje vrabac u ruci nego golub na grani', in our attempt to find out why some modified proverbs seem to be funnier than some others. We have found several other examples and the first to be analysed here is the following: 'bolje ćevap u ruci nego janje na grani' (lit. better to have cevap in one's hand than lamb roast on the branch). Ćevap is a type of popular inexpensive fast food of oriental origin made of minced meat that is very popular in Croatia. Lamb, on the other hand, is an expensive type of meat eaten during some festive occasions. What makes this expression witty is that a proverb is creatively used to express that a person is more willing to 
satisfy his/her hunger immediately than to be patient, bide his/her time and thus earn a potential reward of being able to dine a more expensive cut of meat.

The play on words that we witnessed in all examples analysed in the previous section, e.g. 'bolje šljiva u ruci nego na oku' (lit. a plum in the hand is better than a plum on the eye [i.e. black eye]), 'bolje šećer u škartocu nego u krvi' (lit. better to have sugar in a small paper bag than to have sugar in one's blood), is missing here, but what makes the expression still witty to a certain extent is that its author exploits one of the domains that people tend to exploit when wanting to achieve humorous effect - in this case food.

The second modified proverb that we found in our corpus is the following: 'bolje mig u ruci nego F-16 na grani' (lit. better to have a Mig in one's hand than F-16 on the branch). This was a newspaper headline about the purchase planned by the Croatian Government of military aircrafts on a low budget. Mig refers to the cheaper alternative, which is to repair old and obsolete Russian aircrafts Croatia already owns, whereas F-16 refers to the more expensive option purchase of modern aircraft. Since the budget is low, the choice seems to be obvious.

Now, when we compare this modified proverb to those already analysed, this one seems to be the least humorous, or to put it differently, it does not seem to add any humour to the original proverb. ${ }^{2}$ It only states the reasonable conclusion one can arrive at after reading the newspaper article it introduces. The elements missing, which can probably account for the lack of humour, are plays on words and exploitation of some aspects of human life that are commonly exploited in humour.

It seems that we find humorous those proverbs that require of us some effort in the deconstruction of their meaning. We find some gratification in being able to recognise puns, plays on words, metonymies, or any other sort of verbal riddles.

\section{Conclusion}

Unlike traditional proverbs, modified proverbs are not created to teach us something, to elucidate some aspects of human life or provide us with the useful experience of previous generations. They are also not cognitively economical in that they - through being conventional and entrenched like traditional proverbs - would immediately allow us to access the intended meaning. Quite contrary, their purpose is to entertain us and, in doing so, they place in front of us obstacles in the form of lexical incongruity we need to overcome. It is only after doing so in the process of conceptual (dis)integration that we are able to acknowledge the humour intended.

If we return to the research questions we have started with, we could conclude that linguistic humour theories and tools provided within the framework of cognitive linguistics complement each other in the analysis of humorous modified proverbs. Linguistic humour theories provide us with the notion of resolvable incongruity, but cognitive linguistics provides us with the tools to explain which cognitive mechanisms are involved in the interpretation, how the recipient of the verbalised humour resolves that incongruity, and how s/he interprets the message.

Our analysis has shown that in the case of humorous modified proverbs we mostly rely on the theory of conceptual integration and metonymy. The theory of conceptual integration is particularly suitable for the interpretation of modified proverbs since they present novel structures that are not part of our mental lexicon and which we need to interpret online in dynamic meaning construction. The theory of conceptual integration offers the tools - mental spaces - temporary knowledge structures that we employ for the specific purpose at hand. This is particularly obvious in the case of puns - an indispensable ingredient of most successful jokes - 
which simultaneously point us to two different interpretations, i.e. two different mental spaces, and it is precisely this tension between two possible interpretations that greatly adds to the humour of the modified proverb.

We have also shown that the generic is specific metaphor cannot account for all instances of traditional and modified proverbs, in fact it is suited only for decontextualised traditional proverbs, whereas in all other cases the theory of conceptual integration provides much better framework.

Our examples of humorous modified proverbs have shown that although jokes are verbalised in the form of proverbs, we derive humour from the same mechanisms that are employed in other types of verbal humour: puns, play on words, metonymies, elements of surprise, exploitation of taboos, etc. The evidence for this we find in the fact that those modified proverbs that employ only some of these elements or do not employ any of them are found to be less humorous or not humorous at all.

All these elements of humour, e.g. puns or metonymies, pose riddles which we need to solve to be able to fully appreciate the humour. The more riddles we need to solve and the more effort we need to put into it, the better the gratification derived from the process and the more successful the joke.

\section{Notes}

1 The analysis is in line with Díez Velasco (2001-2: 55-56). Additional patterns of conceptual metaphor and metonymy interaction are to be found in Díez Velasco (2000).

${ }^{2}$ We have conducted a questionnaire survey among 16 university students to establish how they would rate the modified proverbs anaysed in this paper with regard to their humorous effect. All of them rated the proverb 'bolje mig u ruci nego F-16 na grani' as the least humorous.

\section{References}

Attardo, S. (2001). Humorous Texts: A Semantic and Pragmatic Analysis. Humor Research 6. Berlin and New York: Mouton de Gruyter.

Barcelona, A. (2000). 'Introduction. The cognitive theory of metaphor and metonymy', in Barcelona, A. (ed.), Metaphor and Metonymy at the Crossroads. Berlin and New York: Mouton de Gruyter, pp. 1-28.

Barcelona, A. (2003 [2000]). 'On the plausibility of claiming a metonymic motivation for conceptual metaphor', in Barcelona, A. (ed.), Metaphor and Metonymy at the Crossroads. Berlin and New York: Mouton de Gruyter, pp. 31-58.

Brône, G. \& Feyaerts, K. (2004). 'Assessing the SSTH and GTVH: A view from cognitive linguistics’. HUMOR: International Journal of Humor Research 17 (4), pp. 361-372.

Coulson, S. (2001). Semantic Leaps: Frame-Shifting and Conceptual Blending in Meaning Construction. Cambridge: Cambridge University Press.

Coulson, S. (2006). 'Constructing meaning'. Metaphor and Symbol 21 (4), pp. 245-266.

Croft W. (1993). 'The Role of Domains in the Interpretation of Metaphors and Metonymies'. Cognitive Linguistics 4, pp. 335-370.

Deane, P. D. (1992). Grammar in Mind and Brain. Explorations in Cognitive Syntax. Berlin and New York: Mouton de Gruyter. 
Díez Velasco, O. I. (2000). 'A cross-linguistic analysis of the nature of some hand metonymies in English and Spanish'. Atlantis 22 (2), pp. 51-67.

Díez Velasco, O. I. (2001-2). 'Metaphor, metonymy, and image schemas: an analysis of conceptual interaction patterns'. Journal of English Studies (3), pp. 47-63.

Dynel, M. (2009). 'Creative metaphor is a birthday cake: Metaphor as the source of humour'. Metaphorik.de 17, pp. 27-48.

Fauconnier, G. \& Turner M. (1994). 'Conceptual Projection and Middle Spaces'. Technical Report No. 9401. Department of Cognitive Science, University of California: San Diego. Available online: http://www.lit.kobeu.ac.jp/ yomatsum/resources/Fauconnierturner1984.pdf [Accessed 23 November 2015].

Fauconnier, G. \& Turner M. (1999). 'Metonymy and conceptual integration', in Panther, K. \& Radden, G. (eds.), Metonymy in Language and Thought. Amsterdam: John Benjamins, pp. 77-90.

Giora, R. (1991). 'On the cognitive aspects of the joke'. Journal of Pragmatics 16 (5), pp. 465485.

Giora, R. (2003). On Our Mind: Salience, Context and Figurative Language. Oxford - New York - Auckland - Bangkok: Oxford University Press.

Johnson, M. (1987). The Body in the Mind: The Bodily Basis of Meaning, Imagination, and Reason. Chicago: The University of Chicago Press.

Klaić, B. (1962). Rječnik stranih rijeci. Zagreb: Zora.

Koestler, A. (1964). The Act of Creation. London: Hutchinson.

Kövecses, Z. \& Radden, G. (1998). 'Metonymy: Developing a Cognitive Linguistics View'. Cognitive Linguistics 9 (1), pp. 37-77.

Lakoff, G. \& Johnson, M. (1980). Metaphors We Live By. Chicago: The University of Chicago Press.

Lakoff, G. (1987). Women, Fire, and Dangerous Things: What Categories Reveal about the Mind. Chicago: Chicago University Press.

Lakoff, G. \& Turner, M. (1989). More than Cool Reason: A Field Guide to Poetic Metaphor. Chicago: Chicago University Press.

Langacker, R. (1987). Foundations of Cognitive Grammar, Volume I. Stanford. CA: Stanford University Press.

Langacker, R. (1993). 'Reference-Point Constructions'. Cognitive Linguistics 4 (1), pp. 1-38.

Mieder, Wolfgang (1985). 'Popular views of the proverb'. Proverbium 2, pp. 109-143.

Molnar, D. \& Vidaković Erdeljić D. (2009). Paremija u pisanoj javnoj komunikaciji u hrvatskome i engleskom jeziku. Jezikoslovlje (10) 1. Osijek: Filozofski fakultet, pp. 45-58.

Radden, G. \& Kövecses, Z. (1999). 'Towards a theory of metonymy', in Panther, K. \& Radden, G. (eds.), Metonymy in Language and Thought. Human Cognitive Processing 4. Amsterdam - Philadelphia: John Benjamins, pp. 17-59.

Ruiz de Mendoza Ibáñez, F. J. (1998). 'On the nature of blending as a cognitive phenomenon'. Journal of Pragmatics 30 (3), pp. 259-274.

Ruiz de Mendoza Ibáñez, F. J. (1999). 'From semantic underdetermination via metaphor and metonymy to conceptual interaction'. Laud $\mathrm{N}^{\circ}$ 492: Essen. pp. 1-21.

Suls, J. M. (1983). 'Cognitive processes in humor appreciation', in McGhee, P. E. \&. Goldstein, J. H (eds.), Handbook of Humor Research. Volume 1. New York, pp. 39-57.

Schulz, T. R. (1974). 'Order of cognitive processing in humour appreciation'. Canadian Journal of Psychology/Revue canadienne de psychologie 28 (4), pp. 409-420. 
Talmy, L. (2000). Toward a Cognitive Semantics. Two volumes. Cambridge. MA: MIT Press.

Tourangeau, R. \& Sternberg R. (1981). 'Aptness in Metaphor'. Cognitive Psychology 13, pp. 27 55.

Veale, T. (2004). 'Incongruity in Humor. Root cause or epiphenomenon?' HUMOR: International Journal of Humor Research 17 (4), pp. 419-428. 